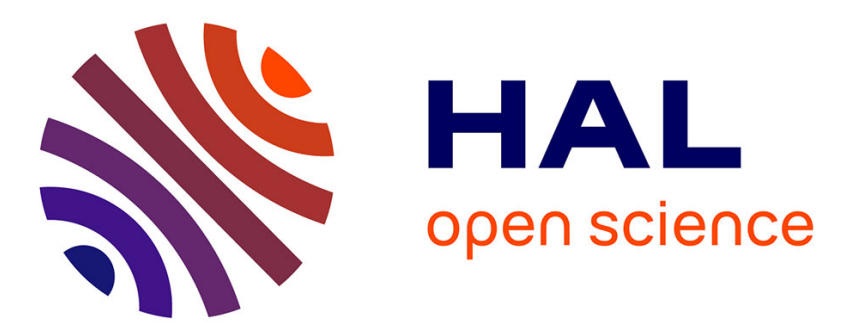

\title{
Information Security Education. Education in Proactive Information Security
}

\author{
Lynette Drevin, Marianthi Theocharidou
}

\section{To cite this version:}

Lynette Drevin, Marianthi Theocharidou. Information Security Education. Education in Proactive Information Security: 12th IFIP WG 11.8 World Conference, WISE 12, Lisbon, Portugal, June 25-27, 2019, Proceedings. Springer International Publishing, AICT-557, 2019, IFIP Advances in Information and Communication Technology, 978-3-030-23450-8. 10.1007/978-3-030-23451-5 . hal-02365723

HAL Id: hal-02365723

https://hal.inria.fr/hal-02365723

Submitted on 15 Nov 2019

HAL is a multi-disciplinary open access archive for the deposit and dissemination of scientific research documents, whether they are published or not. The documents may come from teaching and research institutions in France or abroad, or from public or private research centers.
L'archive ouverte pluridisciplinaire HAL, est destinée au dépôt et à la diffusion de documents scientifiques de niveau recherche, publiés ou non, émanant des établissements d'enseignement et de recherche français ou étrangers, des laboratoires publics ou privés.

\section{(c)(1)}

Distributed under a Creative Commons Attribution| 4.0 International License 


\section{IFIP Advances in Information and Communication Technology}

\section{Editor-in-Chief}

Kai Rannenberg, Goethe University Frankfurt, Germany

\section{Editorial Board Members}

TC 1 - Foundations of Computer Science

Jacques Sakarovitch, Télécom ParisTech, France

TC 2 - Software: Theory and Practice

Michael Goedicke, University of Duisburg-Essen, Germany

TC 3 - Education

Arthur Tatnall, Victoria University, Melbourne, Australia

TC 5 - Information Technology Applications

Erich J. Neuhold, University of Vienna, Austria

TC 6 - Communication Systems

Aiko Pras, University of Twente, Enschede, The Netherlands

TC 7 - System Modeling and Optimization

Fredi Tröltzsch, TU Berlin, Germany

TC 8 - Information Systems

Jan Pries-Heje, Roskilde University, Denmark

TC 9 - ICT and Society

David Kreps, University of Salford, Greater Manchester, UK

TC 10 - Computer Systems Technology

Ricardo Reis, Federal University of Rio Grande do Sul, Porto Alegre, Brazil

TC 11 - Security and Privacy Protection in Information Processing Systems

Steven Furnell, Plymouth University, UK

TC 12 - Artificial Intelligence

Ulrich Furbach, University of Koblenz-Landau, Germany

TC 13 - Human-Computer Interaction

Marco Winckler, University of Nice Sophia Antipolis, France

TC 14 - Entertainment Computing

Rainer Malaka, University of Bremen, Germany 


\section{IFIP - The International Federation for Information Processing}

IFIP was founded in 1960 under the auspices of UNESCO, following the first World Computer Congress held in Paris the previous year. A federation for societies working in information processing, IFIP's aim is two-fold: to support information processing in the countries of its members and to encourage technology transfer to developing nations. As its mission statement clearly states:

IFIP is the global non-profit federation of societies of ICT professionals that aims at achieving a worldwide professional and socially responsible development and application of information and communication technologies.

IFIP is a non-profit-making organization, run almost solely by 2500 volunteers. It operates through a number of technical committees and working groups, which organize events and publications. IFIP's events range from large international open conferences to working conferences and local seminars.

The flagship event is the IFIP World Computer Congress, at which both invited and contributed papers are presented. Contributed papers are rigorously refereed and the rejection rate is high.

As with the Congress, participation in the open conferences is open to all and papers may be invited or submitted. Again, submitted papers are stringently refereed.

The working conferences are structured differently. They are usually run by a working group and attendance is generally smaller and occasionally by invitation only. Their purpose is to create an atmosphere conducive to innovation and development. Refereeing is also rigorous and papers are subjected to extensive group discussion.

Publications arising from IFIP events vary. The papers presented at the IFIP World Computer Congress and at open conferences are published as conference proceedings, while the results of the working conferences are often published as collections of selected and edited papers.

IFIP distinguishes three types of institutional membership: Country Representative Members, Members at Large, and Associate Members. The type of organization that can apply for membership is a wide variety and includes national or international societies of individual computer scientists/ICT professionals, associations or federations of such societies, government institutions/government related organizations, national or international research institutes or consortia, universities, academies of sciences, companies, national or international associations or federations of companies.

More information about this series at http://www.springer.com/series/6102 
Lynette Drevin · Marianthi Theocharidou (Eds.)

\section{Information Security Education}

Education in Proactive Information Security

12th IFIP WG 11.8 World Conference, WISE 12 Lisbon, Portugal, June 25-27, 2019

Proceedings

粤 Springer 


\section{Editors}

Lynette Drevin 10
North-West University
Potchefstroom, South Africa
Marianthi Theocharidou (iD)

European Commission

Joint Research Center

Ispra, Italy

\author{
ISSN 1868-4238 ISSN 1868-422X (electronic) \\ IFIP Advances in Information and Communication Technology \\ ISBN 978-3-030-23450-8 ISBN 978-3-030-23451-5 (eBook) \\ https://doi.org/10.1007/978-3-030-23451-5
}

(C) IFIP International Federation for Information Processing 2019

This work is subject to copyright. All rights are reserved by the Publisher, whether the whole or part of the material is concerned, specifically the rights of translation, reprinting, reuse of illustrations, recitation, broadcasting, reproduction on microfilms or in any other physical way, and transmission or information storage and retrieval, electronic adaptation, computer software, or by similar or dissimilar methodology now known or hereafter developed.

The use of general descriptive names, registered names, trademarks, service marks, etc. in this publication does not imply, even in the absence of a specific statement, that such names are exempt from the relevant protective laws and regulations and therefore free for general use.

The publisher, the authors and the editors are safe to assume that the advice and information in this book are believed to be true and accurate at the date of publication. Neither the publisher nor the authors or the editors give a warranty, expressed or implied, with respect to the material contained herein or for any errors or omissions that may have been made. The publisher remains neutral with regard to jurisdictional claims in published maps and institutional affiliations.

This Springer imprint is published by the registered company Springer Nature Switzerland AG The registered company address is: Gewerbestrasse 11, 6330 Cham, Switzerland 


\section{Preface}

This volume contains the papers presented at the 12th World Conference on Information Security Education (WISE 12) held during June 25-27, 2019, in Lisbon. It was held in conjunction with the 34th IFIP International Conference on Information Security and Privacy Protection (IFIP SEC 2019). WISE 12 was organized by the IFIP Working Group 11.8, which is an international group of people from academia, government, and private organizations who volunteer their time and effort to increase knowledge in the very broad field of information security through education. WG 11.8 has worked to increase information security education and awareness for almost two decades. This year, WG11.8 organized the 12th conference of a successful series under the theme "Education in Proactive Information Security." We received 26 submissions from around the world. Each submission was blind reviewed by at least three international Program Committee members. The committee decided to accept 12 full papers, and thus the acceptance rate for the papers is $46 \%$.

During the conference, a working group discussion addressed the "Graduate Student Pipeline Problem in Cybersecurity." It was chaired by Susanne Wetzel of Stevens Institute of Technology (USA). The topic is driven by surveys and observations in the USA, which indicate a mismatch between open faculty positions in cybersecurity and the number of accepted academic positions from the newly awarded $\mathrm{PhDs}$ in cybersecurity. In fact, the majority of them joined industry. The workgroup discussed the effect on education of the next generation of students in cybersecurity and explored options to address the problem. With high-paying jobs in industry that are already available to graduates from bachelor or master programs, what is the incentive for someone to pursue a $\mathrm{PhD}$ ? What can and needs to be done in order to attract graduates to academic instead of industry jobs?

This conference took place thanks to the support and commitment of many individuals. First, we would like to thank all TC-11 members for continually giving us the opportunity to serve the working group and organize the WISE conferences. Our sincere appreciation also goes to the members of the Program Committee, to the external reviewers, and to the authors who trusted us with their intellectual work. We are grateful for the support of WISE11.8 Officers Lynn Futcher, Matt Bishop, Natalia Miloslavskaya, and Erik Moore. Finally, we would like to thank the local organizers for the support. As for the preparation of this volume, we sincerely thank Erika Siebert-Cole and our publisher Springer for their assistance.

June 2019

Lynette Drevin

Marianthi Theocharidou 


\section{Organization}

\section{Wise12 Conference Chair}

Lynn Futcher

Nelson Mandela University, South Africa

\section{WISE12 Program Chair}

Lynette Drevin

North-West University, South Africa

\section{WISE12 Conference Secretariat}

Matt Bishop

University of California, Davis, USA

\section{WISE12 Publications Chair}

Marianthi Theocharidou European Commission, Joint Research Centre, Italy

\section{WISE12 Local and Logistics Chair}

Natalia Miloslavskaya

National Research Nuclear University MEPhI, Russia

\section{WISE12 Web Chair}

Erik Moore

Regis University, Colorado, USA

\section{Program Committee}

\author{
Maria Bada \\ Matt Bishop \\ Jun Dai \\ Melissa Dark \\ Lynette Drevin \\ Steven Furnell \\ Lynn Futcher \\ Ram Herkanaidu \\ Lech Janczewski \\ Audun Josang \\ Christos Kalloniatis \\ Sokratis Katsikas \\ Basel Katt
}

\author{
University of Cambridge, UK \\ University of California, Davis, USA \\ California State University, Sacramento, USA \\ Purdue University, USA \\ North-West University, South Africa \\ Plymouth University, UK \\ Nelson Mandela Metropolitan University, South Africa \\ Plymouth University, UK \\ The University of Auckland, New Zealand \\ University of Oslo, Norway \\ University of the Aegean, Greece \\ Center for Cyber and Information Security, NTNU, \\ Norway \\ Norwegian University of Science and Technology, \\ NTNU, Norway
}


Siddharth Kaza

Andrea Kolberger

Elmarie Kritzinger

Hennie Kruger

Wai Sze Leung

Dan Likarish

Javier Lopez

Edgar Alonso Lopez-Rojas

Annlize Marnewick

Natalia Miloslavskaya

Stig Mjolsnes

Erik Moore

Ida Ngambeki

Jason Nurse

Ruxandra F. Olimid

Jacques Ophoff

Günther Pernul

Carlos Rieder

Rudi Serfontein

Chien-Chung Shen

Marianthi Theocharidou

Alexander Tolstoy

Ismini Vasileiou

Sune von Solms

Susanne Wetzel

Louise Yngstrom

Sergey Zapechnikov
Towson University, USA

University of Applied Sciences, Upper Austria

UNISA, South Africa

North-West University, South Africa

University of Johannesburg, South Africa

Regis University, Colorado, USA

University of Malaga, Spain

Norwegian University of Science and Technology, NTNU, Norway

University of Johannesburg, South Africa

National Research Nuclear University MEPhI, Russia

Norwegian University of Science and Technology, Norway

Regis University, Colorado, USA

Purdue University, USA

University of Kent, UK

Norwegian University of Science, Norway and

Technology and University of Bucharest, Romania

University of Cape Town, South Africa

Universität Regensburg, Germany

isec ag, Switzerland

North-West University, South Africa

University of Delaware, USA

European Commission, Joint Research Centre, Italy

National Research Nuclear University MEPhI, Russia

Plymouth University, UK

University of Johannesburg, South Africa

Stevens Institute of Technology, USA

Stockholm University, Sweden

National Research Nuclear University MEPhI, Russia

\section{Additional Reviewer}

Ludwig Englbrecht 


\section{Contents}

\section{Innovation in Curricula}

An Educational Intervention for Teaching Secure Coding Practices . . . . . . . . 3 Vuyolwethu Mdunyelwa, Lynn Futcher, and Johan van Niekerk

Learning Principles and the Secure Programming Clinic. . . . . . . . . . . 16 Matt Bishop, Melissa Dark, Lynn Futcher, Johan Van Niekerk, Ida Ngambeki, Somdutta Bose, and Minghua Zhu

Introducing Research into the Undergraduate Curriculum in Cybersecurity . . . 30 Dimitrios Damopoulos and Susanne Wetzel

\section{Training}

A Short-Cycle Framework Approach to Integrating Psychometric

Feedback and Data Analytics to Rapid Cyber Defense. . . . . . . . . . . . . . .

Erik L. Moore, Steven P. Fulton, Roberta A. Mancuso,

Tristen K. Amador, and Daniel M. Likarish

Identifying Security Requirements Body of Knowledge for the Security

Systems Engineer . . . . . . . . . . . . . . . . . . . . .

Suné von Solms and Annlizé Marnewick

Andragogy as a Scientific Basis for Training Professionals

in Information Security . . . . . . . . . . . . . . . . . . . .

Alexander Tolstoy and Natalia Miloslavskaya

\section{Applications and Cryptography}

Light Cryptography . . . . . . . . . . . . . . . . . . . . . . . . . . . .

Pascal Lafourcade, Takaaki Mizuki, Atsuki Nagao, and Kazumasa Shinagawa

Blockchain and Its Security: Ignore or Insert into Academic Training? . . . . .

Natalia Miloslavskaya and Alexander Tolstoy

Identifying Information Security Risks in a Social Network Using Self-organising Maps. . . . . . . . . . . . . . . . .

Rudi Serfontein, Hennie Kruger, and Lynette Drevin 


\section{Organisational Aspects}

Lessons Learned from an Organizational Information Security

Awareness Campaign

Juan-Marc Scrimgeour and Jacques Ophoff

A Comprehensive Framework for Understanding Security Culture

in Organizations

Alaa Tolah, Steven M. Furnell, and Maria Papadaki

Using Gamification to Improve Information Security Behavior:

A Password Strength Experiment

Jacques Ophoff and Frauke Dietz.

Author Index 